\title{
CLINICAL PROFILE OF HYPOPIGMENTARY AND DEPIGMENTARY DISORDERS OF FACE IN PRE-TEEN CHILDREN ATTENDING TERTIARY CARE CENTRE OF NORTH-EAST INDIA
}

\author{
Kinnor Das ${ }^{1}$ Bhaskar Gupta²
}

${ }_{1}^{1}$ Postgraduate Trainee, Department of DVL, Silchar Medical College, Silchar, Assam, India.

2Professor and HOD, Department of DVL, Silchar Medical College, Silchar, Assam, India.

ABSTRACT

\section{BACKGROUND}

Hypopigmentary and Depigmentary disorders form a major burden of pre-teen disease. The study objectives were to evaluate the clinical profile of hypopigmentary and depigmentary disorders in pre-teen patients who attended the Dept. of Dermatology of a tertiary care centre of North-Eastern India. Vitiligo, pityriasis versicolor, pityriasis alba, nevus anemicus, nevus depigmentosus, post-inflammatory hyperpigmentation, atopic dermatitis, tinea incognito and seborrhoeic dermatitis were the diseases we came across and included in our study.

\section{MATERIALS AND METHODS}

The case records of initial 100 children who attended Department of Dermatology with hypopigmentary and depigmentary lesions from Jan 2018 were studied. Proper history was taken, and appropriate investigations were done.

\section{RESULTS}

In our study, pityriasis alba consisted of maximum number of cases, 32\% followed by pityriasis versicolor.

\section{CONCLUSION}

Hypopigmentary disorders on the face of pre-teen children must be identified at the earliest and after diagnosing proper communication with the child and the parents must be done.

\section{KEY WORDS}

Pre-Teen, Preadolescent, Hypopigmentation, Depigmentation.

HOW TO CITE THIS ARTICLE: Das K, Gupta B. Clinical profile of hypopigmentary and depigmentary disorders of face in pre-teen children attending tertiary care centre of North-East India. J. Evolution Med. Dent. Sci. 2018;7(36):3979-3983, DOI: $10.14260 /$ jemds/2018/889

\section{BACKGROUND}

The pre-teen age period is also known as preadolescent period. There are various definitions available for the preteen or preadolescent period, but according to MerriamWebster online dictionary it is the period of human development just preceding adolescence. Specifically, the period between the approximate ages of 9 and $12^{[1]}$ and we have used this age period for our study purpose. This age period can be associated with a lot of mental challenges and anxieties.

The most common Indian skin type according to Fitzpatrick's Phototype has been found to be of type $\mathrm{V}$ followed by type IV,[2] and hypopigmentation in darker skinned patients is more pronounced and hence more disturbing for the patient. Many diseases are age specific and can be commonly found in this age group, but the diseases of hypopigmentation and depigmentation are of particular importance, as it is having psychological impact in growing child due to its cosmetic importance and associated social stigma. Due to unawareness, it may be distressing for the growing child and their parents.

'Financial or Other Competing Interest': None.

Submission 26-07-2018, Peer Review 21-08-2018,

Acceptance 27-08-2018, Published 03-09-2018.

Corresponding Author:

Dr. Kinnor Das,

Old PG Hostel, Room No. 32,

Silchar Medical College,

Ghungoor-788014, Assam, India.

E-mail: daskinnor.das@gmail.com

DOI: $10.14260 /$ jemds $/ 2018 / 889$

\section{(c) (i) $(5)$}

In many parts of India due to lack of awareness and deep rooted superstitions, disease like vitiligo is still considered to be the result of curse and punishment of previous birth sins![3]

We studied the various cases of hypopigmentary and depigmentary disorders who attended the outpatient department of Dermatology at Silchar Medical College, Silchar situated at Assam, India.

The diseases which we came across and included in our study are Vitiligo, Pityriasis versicolor, Pityriasis alba, Nevus anemicus, Nevus depigmentosus, Post-inflammatory hyperpigmentation, Atopic dermatitis, Tinea incognito and Seborrhoeic dermatitis. We also considered indeterminate leprosy or our study.

Vitiligo is considered an acquired disorder of pigmentation. It is characterised by well-defined milky white or chalky white macules or patches. There may be depigmented hairs inside the lesion and there is absence of scaling. Facial vitiligo occurs most commonly around eyes and mouth. Its prevalence worldwide is estimated to be 0.5 $2 \%$. Although, the average age of onset is in late $2^{\text {nd }}$ decade, it can appear any time from childhood to late adulthood. In a study by Shah et al,[4] incidence of vitiligo among new patients was $1.84 \%$ and the female-to-male was 2.1: 1 . According to a couple of Indian studies, the reported prevalence was $26 \%$ from south India and $23.3 \%$ from north India [5] The diagnosis of vitiligo can be done clinically. Wood's lamp can aid in diagnosis of evolving vitiligo and to differentiate it from other depigmentary lesions. In Wood's lamp examination, chalky white-dull blue-white colour is 
seen If histopathology is done then there is absence of melanocytes or present is very small number.[6],[7]

Pityriasis versicolor is also known as tinea versicolor. It is a superficial fungal infection caused by Malassezia spp, which is a dimorphic fungus, which is a member of normal flora of skin.[8] Clinically, it is characterised by numerous fine scaly, dyspigmented irregular macules most often occurring on the trunk, chest and proximal part of upper limbs.[9] Most of the times it is hypopigmented, but hyperpigmented lesions have been noted as well. There are a lot of theories explaining the cause of hypopigmentation in pityriasis versicolor, but the production of dicarboxylic acid, especially azelaic acid produced by Malassezia furfur which inhibits tyrosinase is widely accepted. Hyperpigmentation in a lesion of Pityriasis versicolor has been explained by abnormally large melanosomes, a thick stratum corneum and a hyperaemic inflammatory response.[10] Pityriasis versicolor tends to recur very often. Malassezia can be identified by skin scraping with $10 \% \mathrm{KOH}$ mount.[11]

Pityriasis alba is a low-grade dermatitis.[9] Clinically manifested as poorly defined hypopigmented macules or patches with fine scales. In Latin, alba means white. The lesions are more prominent in cold temperatures. In the minor diagnostic signs for Atopic Dermatitis by Hanifin and Rajka, Pityriasis alba is a minor criterion. [Rook] According to a study by Vinod et al done in patients of 8 months to 32 years age, face was involved in $91 \%$ cases with Male-toFemale ratio being 1.35: 1.[12] The diagnosis can be made clinically and histopathology, usually not required. $10 \% \mathrm{KOH}$ mount of skin scarping do not reveal any fungal elements, as there is no infective aetiology.

Nevus anemicus was first described by Hans Vörner in 1906, hence called as Verner's nevus. The lesions are present since birth, most commonly on trunk and rarely on face and they are usually solitary. They are well-defined and irregular in shape. The lesion is usually non-progressive. There is increased response to catecholamines which results in characteristic lesion of the skin, as a result it is occasionally called as a pharmacological nevus. When we rub the skin lesion, there is no erythema.[13] The lesion merges with surrounding skin when diascopy is done. If histological examination is done, we can find a normal presence of melanocytes and melanin. On Wood's lamp examination, the colour is not accentuated.

Nevus depigmentosus is also known as achromic nevus. It is present since birth. It is occasionally associated with central nervous system anomalies. Occasionally, there may be splashed paint appearance. It is found mostly on the trunk, neck, face and proximal part of the extremities. Three types of achromic nevus has been described clinically: Localised, segmental and linear or whorled. Localised variant is the most common. Diascopy test is negative, which is positive in nevus anemicus and on Wood's lamp examination we can observe an off-white colour.[14]

\section{There is a Criteria given by Coup in 1976 for Achromic Nevus[15]}

1. Leukoderma, which is early in onset or is present at birth.

2. Throughout life, there is no alteration in distribution of lesion.
3. Throughout life, there is no alteration in texture or sensation in lesion.

4. There is no hyperpigmented border.

Seborrheic dermatitis is a type of endogenous eczema.[8] It can affect up to $11.6 \%$ of population.[16] If we consider facial seborrheic dermatitis, then it is most commonly distributed in the nasolabial fold, the medial part of the eyebrows, around glabella or the eye lashes. [Rooks] The lesions are associated with greasy scaling and the lesions are usually bilaterally symmetrical in distribution. There is associated history of scaling of the scalp and involvement of other seborrheic areas of body. The diagnosis of Seborrheic dermatitis was made clinically. On dermatoscopy, arborizing vessels were seen. ${ }^{[8]}$ The children with seborrheic dermatitis were managed by prescribing topical antifungals combination with corticosteroids.

Atopic dermatitis is a form of endogenous eczema like seborrheic dermatitis. The symptoms of atopic dermatitis usually start in infancy. Atopic dermatitis can be infantile (Age less than 2 years), childhood (Age between 2 to 12 years), adolescent (Age more than 12 years) and senile (Age more than 60 years).[7] Darker skinned children can have perifollicular hypopigmented lesions that can merge to form larger areas. According to one study, Face can be involved in up to $25 \%$ cases of atopic dermatitis.[17] Hanifin and Rajka's criteria can be used to diagnose atopic dermatitis. For the management, the first line is emollients. Oral antihistaminics is needed for pruritus, which is the main complaint of atopic dermatitis. Topical corticosteroids and immunomodulators can be used based on the requirement. Wet wrap therapy, and proper bathing practices can help. ${ }^{[18]}$

Tinea incognito: Tinea infection is caused by dermatophytes. Tinea faciei is the dermatophyte infection of face excluding beard and moustache area in a post-pubertal male.[19] Although, the incidence of tinea of the face is less common, but now-a-days due to epidemic of tinea it has become very common. The patients' attendants prefer to apply topical corticosteroid combination creams and other compounds like dithranol (1, 8-dihydroxy-9, 10dihydroanthracen-9-one) as a result of which the morphology of typical lesion changes and results in various appearances. As a result of this, it is called as tinea incognito.[20] Incognito means having one's true identity concealed. Just like incognito mode of web browser hide the IP address, the tinea incognito hides the typical clinical character of the disease. One of the many presentations of tinea incognito may be hypopigmentation of the face, which we considered and included in this study. The hypopigmentation is also associated with erythema and scaling of that area. The child may complain of burning or itching of that area. For the diagnosis of tinea incognito, we can take proper history which will reveal typical lesion morphology and application history of topical corticosteroids or other chemicals. The fungal aetiology can be caught by performing $\mathrm{KOH}$ examination from the skin scrapings. Tinea faciei can be treated by topical antifungals or a combination of topical and oral antifungals. If associated irritant contact dermatitis is present, then we can use mild topical corticosteroid for couple of days, just to weeks to reduce the inflammation.

Post-inflammatory hyperpigmentation: Cutaneous inflammatory conditions, cutaneous injury from burns, 
contact with irritants and post dermatological procedures can cause hypopigmentation rather than hyperpigmentation. 'Individual chromatic tendency' was proposed by Ruiz-Maldonado to describe this entity.[21 Chromatic tendency is determined genetically and inherited autosomal dominant pattern. Milder forms can resolve within few weeks. Treatment of post-inflammatory hypopigmentation involves removal of offending agent first. Application of mild topical corticosteroid may be beneficial. Calcineurin inhibitors, sun exposure can help. ${ }^{[22]}$

Indeterminate leprosy is usually found in a child and the clinical presentation is usually a hypopigmented to erythematous patch, whose borders are ill defined. Most of the times the lesions are solitary and found on face. Anaesthesia is absent and slit skin smear is negative. It may heal by itself or $30 \%$ of times it may progress to any of the determinate types.[23] If indeterminate leprosy is suspected, then it must be followed up for its progression.

Study objectives were to study the clinical profile of hypopigmentary and depigmentary disorders in pre-teen patients who attended the Dept. of Dermatology of a tertiary care centre of North-Eastern India. Vitiligo, Pityriasis Versicolor, Pityriasis alba, Nevus anemicus, Nevus depigmentosus, Post-inflammatory hyperpigmentation, Atopic dermatitis, Tinea incognito and Seborrhoeic dermatitis were the diseases we came across and included in our study.

\section{MATERIALS AND METHODS}

Our study is an observational study of children attending Department of Dermatology at Silchar Medical College, Silchar (Assam), which was done after taking approval from the Institute Ethics Committee. The case records of first 100 children who were aged from 9 years to 12 years and presented with hypopigmentation and depigmentation from $1^{\text {st }}$ January 2018 was studied. Data of patients like age, gender, family history and history of trauma was noted. Chief complaint, duration of present illness, previous treatment and history of application of topical drugs and chemicals was noted. Diagnosis was based on available medical history given by children and their guardians, clinical evaluation of each lesions and appropriate investigations. Investigations like Wood's Lamp examination, skin scraping for fungal elements, diascopy and dermatoscopy were used. We advised punch biopsy to all patients' guardians for a definitive diagnosis, but due to cosmetic concerns, they did not give their consent. Counselling was done to patients' attendants regarding the aetiology and course of disease. The various modalities of treatment available and the prognosis was explained to them. During our counselling, we tried to wean off their superstition regarding these diseases. Microsoft office 2007 was used for the statistical analysis. Descriptive statistics like mean and percentages were used for the analysis.

\section{RESULTS}

Among the one hundred children, we studied the mean age was $11.7 \pm 0.9$ years. Out of the total number of patients, $58 \%$ were female and $42 \%$ were male (Chart 1). The higher percentage of female reporting to Outpatient Department was due to more concern of parents regarding altered complexion of female child, which may hamper the marriage proposals in future as stated by the parents of some of the female children.

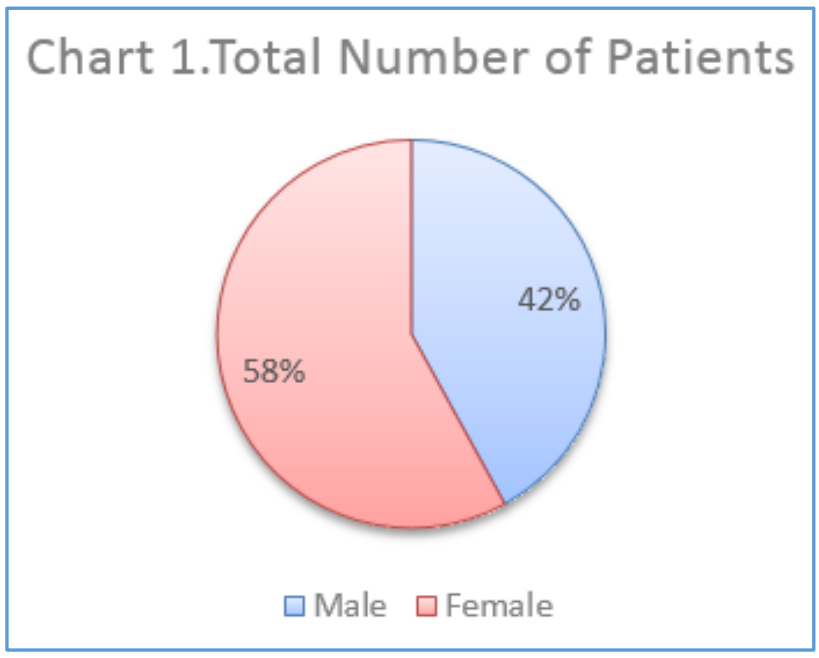

The distribution of cases has been shown in Chart 2 . Pityriasis alba consisted of maximum number of cases (32\%) followed by Pityriasis versicolor (28\%). Vitiligo, which is associated with much of social stigma in India was diagnosed in only $3 \%$ of cases. There were no cases of indeterminate leprosy in our study.

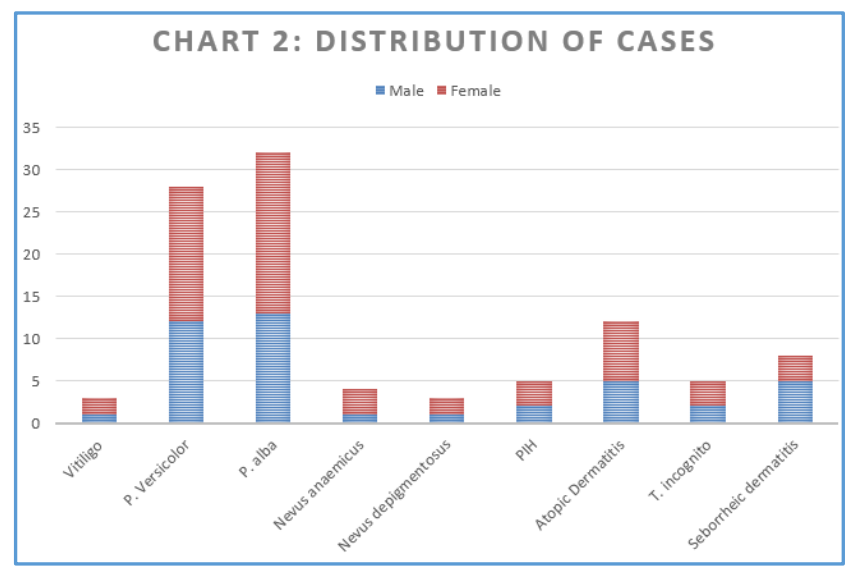

\begin{tabular}{|c|c|c|c|}
\hline & Male & Female & Total Cases \\
\hline Vitiligo & 1 & 2 & 3 \\
\hline $\begin{array}{l}\text { Pityriasis } \\
\text { Versicolor }\end{array}$ & 12 & 16 & 28 \\
\hline Pityriasis alba & 13 & 19 & 32 \\
\hline Nevus anemicus & 1 & 3 & 4 \\
\hline $\begin{array}{c}\text { Nevus } \\
\text { depigmentosus }\end{array}$ & 1 & 2 & 3 \\
\hline $\begin{array}{l}\text { Post-inflammatory } \\
\text { hypopigmentation }\end{array}$ & 2 & 3 & 5 \\
\hline Atopic dermatitis & 5 & 7 & 12 \\
\hline Tinea incognito & 2 & 3 & 5 \\
\hline $\begin{array}{c}\text { Seborrheic } \\
\text { dermatitis }\end{array}$ & 5 & 3 & 8 \\
\hline Total & 42 & 58 & 100 \\
\hline
\end{tabular}




\section{Clinical Images}

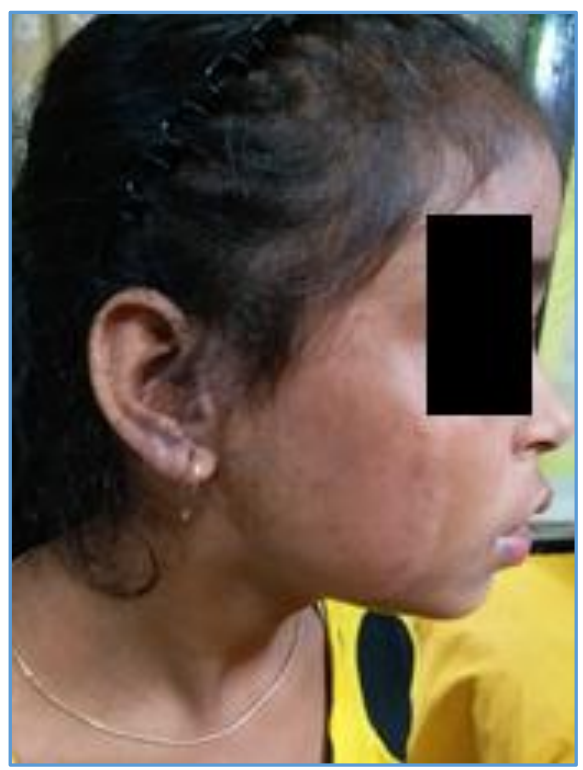

Tinea incognito (11 yrs./Female)

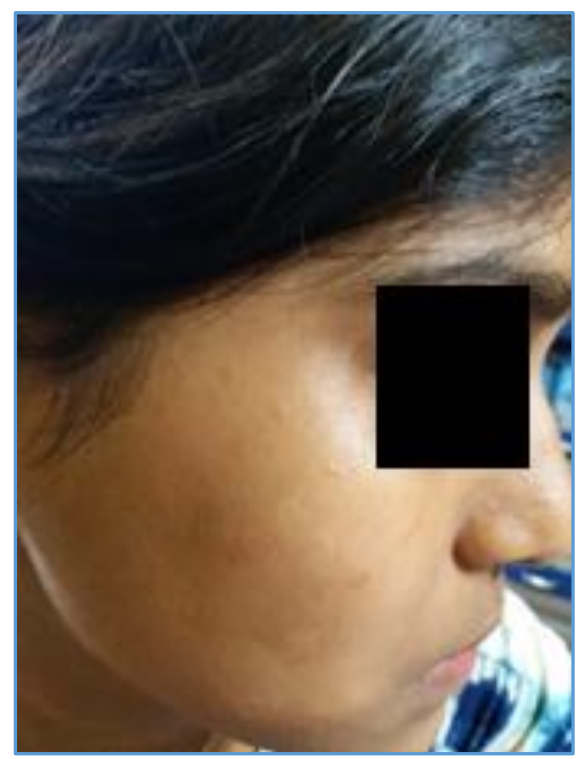

Pityriasis alba (12 yrs./Female)

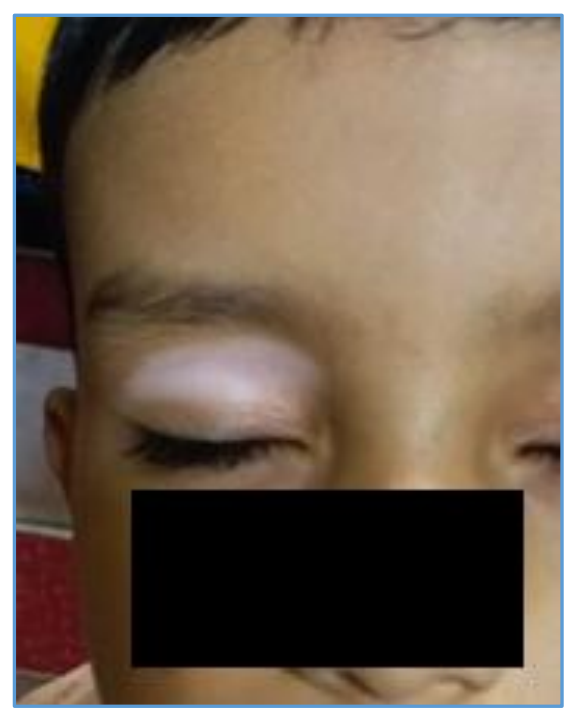

Vitiligo (9 yrs./Male)

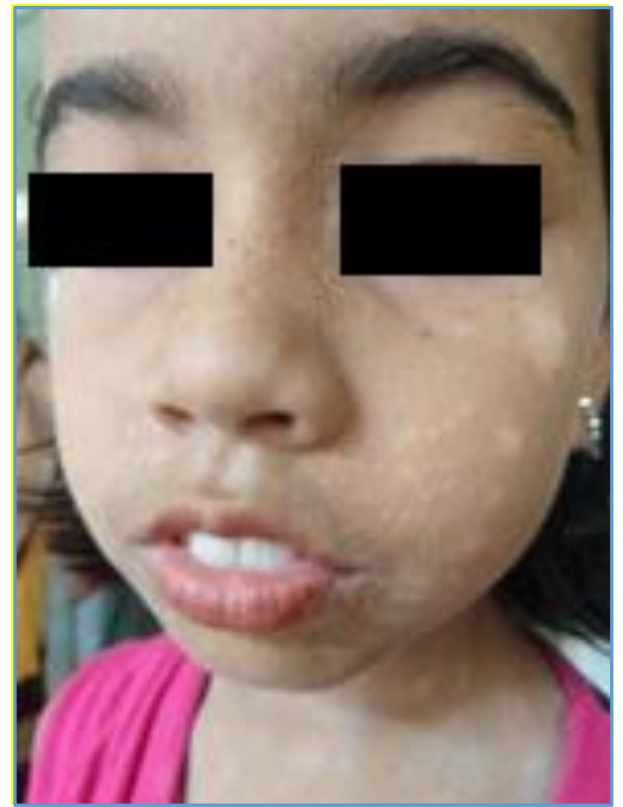

Pityriasis alba (10 yrs./Female)

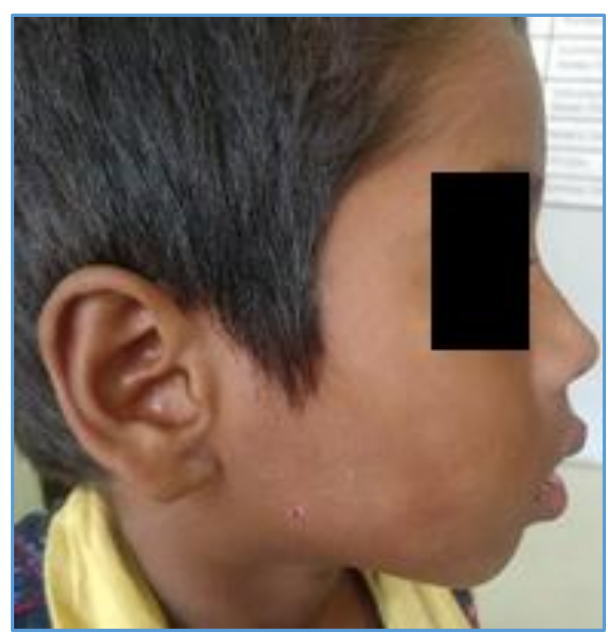

Pityriasis alba (9 yrs./Male)

\section{DISCUSSION}

The aetiology of the hypopigmentary and depigmentary lesions over the face of a pre-teen child varies, also the pathogenesis. As a result, the treatment modalities of each disorder vary, and the prognosis of each disorder is different. Vitiligo can have a chronic course, whereas nevus depigmentosus will remain same throughout life. If the primary aetiology is infective, then proper antimicrobial therapy will resolve the disease. Hence, it becomes important for the dermatologists not only to understand the aetiology, but also to explain it to the growing child and their patents.

\section{CONCLUSION}

This study covers most of the hypopigmentary and depigmentary lesions that a dermatologist comes across. When these lesions are present in a pre-teen child, this can be distressing for the family and growing child. Therefore, correct identification and treatment along with proper counselling to patient and their parents regarding the outcome and treatment option is absolutely necessary to avoid social stigma. 


\section{Limitations of the Study}

The current study was conducted with less number of cases. Also, histopathology of the lesions could not be done.

\section{REFERENCES}

[1] https://www.merriamwebster.com/dictionary/preadolescence

[2] Sachdeva S. Fitzpatrick skin typing: applications in dermatology. Indian J Dermatol Venereol Leprol 2009;75(1):93-6.

[3] Pandve HT. Vitiligo: Is it just a dermatological disorder? Indian J Dermatol 2008;53(1):40-1.

[4] Shah H, Mehta A, Astik B. Clinical and sociodemographic study of vitiligo. Indian J Dermatol Venereol Leprol 2008;74(6):701.

[5] Palit A, Inamadar AC. Childhood vitiligo. Indian J Dermatol Venereol Leprol 2012;78(1):30-41.

[6] Venkataram. Fundamentals of pathology of skin. Mysore: Anshan Ltd., 2006.

[7] Bolognia JL, Schaffer JV, Cerroni L. Dermatology. 4th edn. Philadelphia, PA: Elsevier 2018.

[8] Griffiths C, Barker J, Bleiker T, et al. Rooks Textbook of Dermatology. 9th edn. Wiley-Blackwell 2016.

[9] Bandyopadhyay, Debabrata. Manual of dermatological differential diagnosis. 1 ${ }^{\text {st }}$ edn. CBS Publishers \& Distributors Pvt. Ltd., 2016.

[10] Gupta D, Thappa DM. The enigma of color in tinea versicolor. Pigment Int 2014;1(1):32-5.

[11] Ghosh SK, Dey SK, Saha I, et al. Pityriasis versicolor: a clinicomycological and epidemiological study from a tertiary care hospital. Indian J Dermatol 2008;53(4):182-5.

[12] Vinod S, Singh G, Dash K, et al. Clinico epidemiological study of pityriasis Alba. Indian J Dermatol Venereol Leprol 2002;68(6):338-40.
[13] Van Geel N, Speeckaert M, Chevolet I, et al. Hypomelanoses in Children. Journal of Cutaneous and Aesthetic Surgery 2013;6(2):65-72.

[14] Deb S, Sarkar R, Samanta AB. A brief review of nevus depigmentosus. Pigment Int 2014;1(2):56-8.

[15] Coup RL. Unilateral systemic achromic naevus. Dermatologica 1976;136:19-35.

[16] Araya M, Kulthanan K, Jiamton S. Clinical characteristics and quality of life of seborrheic dermatitis patients in a tropical country. Indian J Dermatol 2015;60(5):519.

[17] Sehgal VN, Srivastava G, Aggarwal AK, et al. Atopic dermatitis: a cross-sectional (descriptive) study of 100 cases. Indian J Dermatol 2015;60(5):519.

[18] Eichenfield LF, Tom WL, Berger TG, et al. Guidelines of care for the management of atopic dermatitis: section 2. Management and treatment of atopic dermatitis with topical therapies. Journal of the American Academy of Dermatology 2014;71(1):116-32.

[19] https://www.dermnetnz.org/topics/tinea-faciei/

[20] Kabir S, Khurana A, Shilpa G, et al. IADVL Manual on management of dermatophytoses. $1^{\text {st }}$ edn. CBS Publishers \& Distributors Pvt. Ltd., 2018.

[21] Ruiz-Maldonado R, Orozco-Covarrubias ML. Postinflammatory hypopigmentation and hyperpigmentation. Semin Cutan Med Surg 1997;16(1):36-43.

[22] Vachiramon V, Hadanipon K. Postinflammatory hypopigmentation. Clinical and Experimental Dermatology 2011;36(7):708-14.

[23] Jopling WH, McDougall AC. Handbook of leprosy. $5^{\text {th }}$ edn. New Delhi: CBS Publications 1996. 